\title{
Influence of body mass index on postoperative complications after thymectomy in myasthenia gravis patients
}

\author{
Xu-Dong Liu' ${ }^{1,2}$, Ming-Rui Shao ${ }^{1}$, Lei Sun ${ }^{1}$, Lin Zhang ${ }^{1}$, Xin-Shan Jia ${ }^{3,4}$ and Wen-Ya Li ${ }^{1}$ \\ ${ }^{1}$ Department of Thoracic Surgery, The First Affiliated Hospital of China Medical University, Shenyang, Liaoning Province, \\ China \\ ${ }^{2}$ Department of Rheumatology and Immunology, The First Affiliated Hospital of China Medical University, Shenyang, Liaoning \\ Province, China \\ ${ }^{3}$ Department of Pathology, The First Affiliated Hospital of China Medical University, Shenyang, Liaoning Province, China \\ ${ }^{4}$ Department of Pathology, College of Basic Medical Sciences, China Medical University, Shenyang, Liaoning Province, China \\ Correspondence to: Wen-Ya Li, email: saint5288@hotmail.com \\ Keywords: myasthenia gravis, body mass index, postoperative complications, thymectomy \\ Abbreviations: ANOVA: analysis of variance; BMI: body mass index; MG: Myasthenia gravis; PRF: postoperative respiratory \\ failure; ROC: receiver operating characteristic
}

Received: February 14, $2017 \quad$ Accepted: June 10, 2017

Published: July 12, 2017

Copyright: Liu et al. This is an open-access article distributed under the terms of the Creative Commons Attribution License 3.0 (CC BY 3.0), which permits unrestricted use, distribution, and reproduction in any medium, provided the original author and source are credited.

\section{ABSTRACT}

Objectives: It is not clear whether being overweight or obese influences postoperative complications in myasthenia gravis (MG) patients. We retrospectively investigated an association between body mass index (BMI) and postoperative complications in MG.

Materials and Methods: Fifty-nine MG patients who had undergone transsternal thymectomy were classified as low or high BMI based on the criteria for Asian-Pacific populations. An association between BMI and complications was analyzed.

Results: MG patients with high BMI had significantly higher rates of major adverse complications $(P=0.033)$, postoperative respiratory failure $(P=0.045)$, and longer postoperative hospitalization $(P=0.005)$. The optimal cutoff value of BMI for postoperative respiratory failure was $23.3 \mathrm{~kg} / \mathrm{m}^{2}$, with a sensitivity of $75.0 \%$ and a specificity of $64.7 \%(P=0.046)$.

Conclusions: MG patients with a BMI indicating overweight or obesity have a higher risk of postoperative complications after thymectomy. Thus, close monitoring must be performed when surgery is necessary.

\section{INTRODUCTION}

Worldwide, it is estimated that 110 million children and adolescents in 2013, and 640 million adults in 2014, were overweight or obese. In 2013 about 4.5 million deaths were related to being overweight or obese [1]. Mounting evidence indicates that obesity is linked to a high risk of multiple serious conditions, including type 2 diabetes, cardiovascular disease, metabolic disturbances, and several cancers [2-7]. Considering the potential for obesity to become a global health crisis, it is not only a chronic health condition but also a disease [8].

Myasthenia gravis (MG) is a common autoimmune disorder that results from neuromuscular transmission abnormalities via several types of autoantibodies. MG is clinically characterized by muscle weakness and fatigue upon mild exertion [9-11]. The annual incidence of MG is 8-10 persons per million, and the prevalence rate is $150-250$ per million [12]. The weakness may be localized or generalized, and the eye muscles are the most affected. MG can become life threatening when respiratory insufficiency occurs, due to involvement of the intercostal and diaphragmatic muscles.

Thymectomy has been shown to benefit MG patients with thymoma or thymic hyperplasia, and also in some patients with non-thymomatous MG [13-15]. However, it is noted that special attention must be paid to MG patients undergoing surgery, since administration of muscle relaxants may aggravate muscle weakness [14].

It has been reported that obesity is associated with higher rates of postoperative complications, but this 
remains controversial [16-18]. Hypoxia can be locally and systemically induced by excessive adipose tissue, and MG is vulnerable to oxygen. We therefore investigated whether body mass index (BMI), an accepted measure of obesity, is associated with postoperative problems in patients with MG, and especially severe complications such as postoperative respiratory failure (PRF).

\section{RESULTS}

\section{Patient characteristics}

The study population comprised 59 patients (25 male, 34 female), with a mean age of 48 years (range 15-70 years; Table 1). The disease course varied from 5 days to 10 years (mean, 234 days). Of these 59 patients, 24 had a mass $\geq 4.6 \mathrm{~cm}$ (mean size). Anti-acetylcholine receptor antibody titers ranged from 1.1 to $12.5 \mathrm{nM}$, evaluated by radioimmunoassay.

The WHO histology classifications were as follows: thymus hyperplasia in 11 cases; type A thymoma in 5 cases; type AB in 7 cases; type B1 in 9 cases; type B2 in 17 cases; and type B3 in 10 cases; Regarding Masaoka stages: $23,24,11$, and 1 patient were at stages I, II, III, and $\mathrm{IV}$, respectively.

The low- and high-BMI groups were statistically comparable with regard to each clinical characteristic (Table 1).

\section{Association between BMI and postoperative complications}

Of the 59 patients, $9(15.3 \%)$ experienced severe postoperative complications that required rescue treatment or secondary surgery: 8 with respiratory failure due to various causes, and 1 with sternal dehiscence (Table 2). Using a logistic regression model, we investigated associations between each of the clinical parameters and major adverse complications, and found that only BMI was a statistical factor (Table 3).

Considering the high incidence of PRF (13.6\%) and subsequent threat to life, we further analyzed the reasons for PRF (Figure 1). Five cases were caused by postoperative myasthenic crisis, and there was one case each of pulmonary infection, bilateral pneumothorax, and pulmonary edema. The patient with pulmonary edema had a long disease history and giant tumor $(17.0 \mathrm{~cm})$. The high-BMI group had a significantly higher incidence of PRF compared with the low-BMI group (Table 4). Based on the receiver operating characteristic (ROC) curve, the cut-off BMI for PRF was determined to be $23.3 \mathrm{~kg} / \mathrm{m}^{2}$. The area under the ROC curve (AUC) was 0.721 with a sensitivity of $75.0 \%$ and a specificity of $64.7 \%$ (95\% CI 0.570-0.871, $P<0.05$; Figure 2).

In addition to the major complications, other clinical monitoring parameters were evaluated (Table 5). These included: operative time (mean, $128 \mathrm{~min}$ ); drainage time (mean, $4 \mathrm{~d}$ ); total drainage volume (mean, $557 \mathrm{~mL}$ ); and postoperative hospital stay (mean, $14 \mathrm{~d}$ ). The postoperative hospital stay of patients in the high-BMI group was significantly longer than that of the low-BMI group $(P=0.005)$. Otherwise, the clinical monitoring parameters of the 2 groups were similar.

\section{DISCUSSION}

In the current study, BMI was positively associated with major postoperative complications in patients with MG after transsternal thymectomy. Of particular note, these complications included PRF, which can be fatal, and which is caused by factors such as thymoma, drugs, pneumonia, surgery, and postoperative myasthenic crisis [19-21]. In the present study, the incidence rate of PRF was significantly higher in the patients of the high-BMI group compared with the low-BMI group $(P=0.045)$. Postoperative myasthenic crisis has a predominant role in PRF, with an incidence of 6-34\% [21-23]. Similarly, myasthenic crisis occurred in $8.5 \%(5 / 59)$ of our patients. Thus, special monitoring care must be planned for overweight or obese MG patients scheduled for thymectomy.

Other reasons also contribute to PRF after surgery in MG patients with high BMI. Hypoxia is a main driver of adipose tissue dysfunction in obesity [24, 25], and oxygen tension activates hypoxia inducible factor-1 (HIF-1), a key factor in the response to low oxygenation, which in turn generates a series of inflammatory responses $[6,26]$. There is no doubt that both hypoxia and systemic inflammation have adverse effects on MG. In addition, obesity is generally considered a high risk factor for postoperative complications [16-18]. This may partially be due to a raised diaphragm, increased chest pressure, and impaired pulmonary function. Hypoxia of the body can also be caused by MG itself, where respiratory muscles are affected. Accordingly, it is logical that a high BMI is tightly linked with PRF, as found in the present study. Furthermore, according to the ROC curve, the optimal cutoff value of BMI for PRF was determined to be $23.3 \mathrm{~kg} /$ $\mathrm{m}^{2}$, with a sensitivity of $75.0 \%$ and a specificity of $64.7 \%$.

Besides major adverse complications, the present study showed that the postoperative hospital stay of patients in the high-BMI group was significantly longer than that of the low-BMI group. That may be a result of higher complication rates in high-BMI group. However, the groups were comparable with regard to operative time, days of drainage, and total drainage volume.

Excessive weight has attracted global attention, not only for its increased incidence, but for its association with cardiovascular disease, diabetes, and many cancers [2-4]. Positive dose-response links between weight and cancer risk have been demonstrated, with $\sim 1.2$ to 1.5 -fold and 1.5 to 1.8 -fold higher risks for overweight and obesity, respectively [1]. High BMI indicates a poor prognosis in breast, colon, liver, and prostate cancer [8, 27-31]. 
Table 1: Basic clinical characteristics of patients with MG stratified by low and high BMI

\begin{tabular}{|c|c|c|c|c|c|}
\hline \multirow{2}{*}{ variables } & \multirow{2}{*}{ Number } & \multicolumn{2}{|c|}{ BMI $\left(\mathrm{kg} / \mathrm{m}^{2}\right)$} & \multirow{2}{*}{$\chi^{2}$} & \multirow{2}{*}{$P$-value } \\
\hline & & low group $(<23.0)$ & High group $(\geqq 23.0)$ & & \\
\hline Age (y) & & & & 0.272 & 0.602 \\
\hline$<48$ & 26 & 14 & 12 & & \\
\hline$\geqq 48$ & 33 & 20 & 13 & & \\
\hline Gender & & & & 0.100 & 0.752 \\
\hline Male & 25 & 15 & 10 & & \\
\hline Female & 34 & 19 & 15 & & \\
\hline Smoking History & & & & 2.508 & 0.113 \\
\hline Yes & 13 & 5 & 8 & & \\
\hline No & 46 & 29 & 17 & & \\
\hline Course (d) & & & & 0.002 & 0.967 \\
\hline$<234$ & 45 & 26 & 19 & & \\
\hline$\geqq 234$ & 14 & 8 & 6 & & \\
\hline Tumor size (cm) & & & & 0.393 & 0.531 \\
\hline$<4.6$ & 35 & 19 & 16 & & \\
\hline$\geqq 4.6$ & 24 & 15 & 9 & & \\
\hline WHO histology ${ }^{\mathrm{a}}$ & & & & 2.170 & 0.825 \\
\hline Hyperplasia & 11 & 5 & 6 & & \\
\hline Type A & 5 & 4 & 1 & & \\
\hline Type AB & 7 & 4 & 3 & & \\
\hline Type B1 & 9 & 6 & 3 & & \\
\hline Thymoma B2 & 17 & 9 & 8 & & \\
\hline Thymoma B3 & 10 & 6 & 4 & & \\
\hline Masaoka stage & & & & 0.003 & 0.956 \\
\hline I + II stage & $47(23+24)$ & $27(13+14)$ & $20(10+10)$ & & \\
\hline III + IV stage & $12(11+1)$ & $7(7+0)$ & $5(4+1)$ & & \\
\hline
\end{tabular}

athymus hyperplasia, type $\mathrm{A} 1, \mathrm{AB}, \mathrm{B} 1, \mathrm{~B} 2, \mathrm{~B} 3$ thymoma.

Table 2: Detailed clinical records of the nine MG patients with severe complications

\begin{tabular}{|c|c|c|c|c|c|c|c|c|c|c|c|}
\hline Case & sex & Age $(y)$ & course & BMI & smoke & Tumor (cm) & Histology & $\begin{array}{c}\text { Masaoka } \\
\text { Stage }^{a}\end{array}$ & Complications & Incubation $^{\mathrm{b}}(\mathrm{d})$ & Outcome $^{\mathrm{C}}$ \\
\hline 1 & M & 50 & 1 year & 27.0 & yes & 2.4 & B2 & II & $\mathrm{MC}$ & 2 & Survived \\
\hline 2 & $\mathrm{~F}$ & 69 & 3 months & 23.3 & No & 8.0 & A & I & MC; PI; MODS & 18 & Died \\
\hline 3 & F & 52 & 4 months & 26.2 & Yes & 5.5 & B1 & I & MC & 7 & Survived \\
\hline 4 & $\mathrm{M}$ & 44 & 3 months & 25.8 & No & 3.0 & $\mathrm{AB}$ & I & Sternal dehiscence & 0 & Survived \\
\hline 5 & $\mathrm{~F}$ & 62 & 1 year & 30.1 & No & 2.0 & B1 & II & MC & 6 & Survived \\
\hline 6 & F & 49 & 7 days & 22.3 & No & 4.8 & B2 & II & PI & 39 & Survived \\
\hline 7 & M & 26 & 10 days & 23.4 & No & 4.0 & B2 & II & Pneumothorax ${ }^{\circ}$ & 4 & Survived \\
\hline 8 & F & 45 & 8 months & 21.4 & No & 17.0 & B1 & III & Pulmonary edema & 10 & Survived \\
\hline 9 & M & 39 & 1 month & 24.7 & Yes & 5.1 & B2 & I & MC & 7 & Survived \\
\hline
\end{tabular}

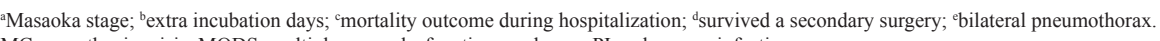

MC, myasthenic crisis; MODS, multiple organ dysfunction syndrome; PI, pulmonary infection. 
Table 3: Association between clinical parameters and major adverse complications in logistic regression model

\begin{tabular}{lccc}
\hline \multicolumn{1}{c}{ Parameters } & \multicolumn{2}{c}{$\mathbf{9 5 \% \mathbf { C I } ^ { \mathbf { b } }}$} & \multirow{2}{*}{$\boldsymbol{P}$-value } \\
\cline { 2 - 3 } & lower & upper & 0.921 \\
\hline Age $(<48$ Vs. $\geqq 48$ years $)$ & 0.203 & 5.841 & 0.799 \\
Gender (Male Vs. Female) & 0.098 & 5.989 & 0.987 \\
Smoking History (Yes Vs. No) & 0.111 & 9.302 & 0.933 \\
Course $(<234$ Vs. $\geqq 234$ days $)$ & 0.130 & 6.497 & $0.033^{*}$ \\
BMI $(<23.0$ Vs. $\geqq 23.0)$ & 1.179 & 44.564 & 0.225 \\
Tumor size $(<4.6$ Vs. $\geqq 4.6$ cm) & 0.531 & 14.790 & 0.611 \\
WHO histology & 0.106 & 3.732 & 0.829 \\
(Hyperplasia + A1 + AB Vs. B1 + B2 + B3) & 0.158 & 9.968 & \\
Masaoka stage (I + II Vs. III + IV stage) & & & \\
\hline
\end{tabular}

${ }^{a}$ WHO histology, thymus hyperplasia, type A1, AB, B1, B2, B3 thymoma.

${ }^{\mathrm{b}}$ confidence interval.

${ }^{*} P<0.05$.

Myasthenic crisis

Pulmonary infection

Pulmonary edema

Pneumothorax

Total=8

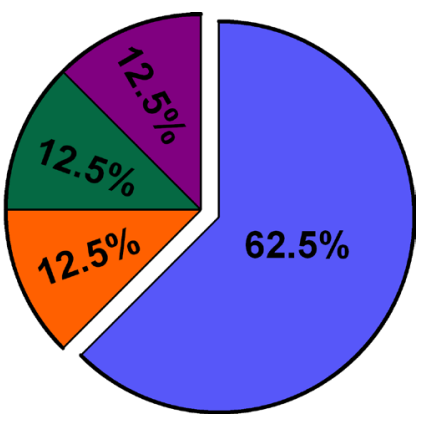

Figure 1: Causes of PRF.

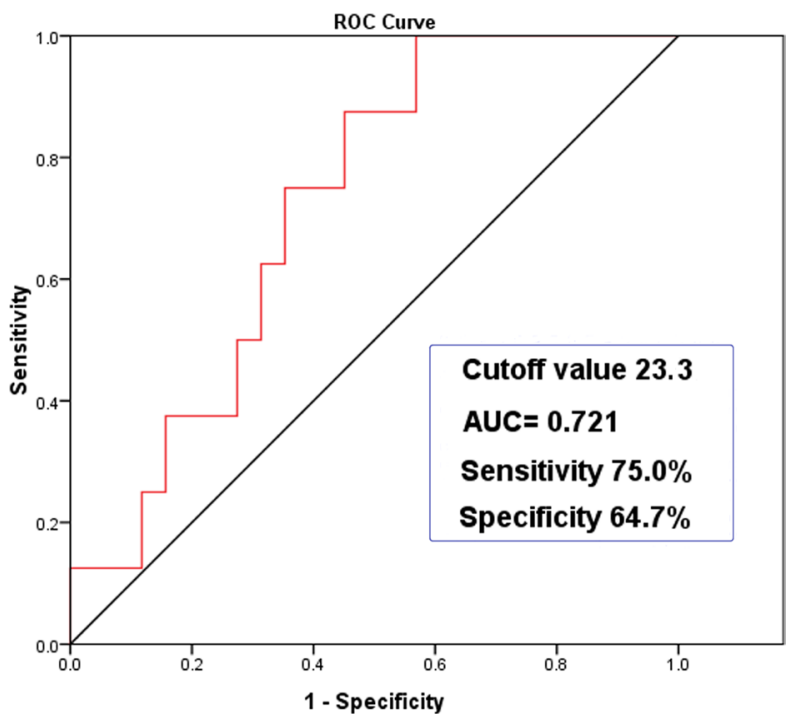

Figure 2: ROC curve analysis of BMI with PRF $(95 \%$ CI $0.570-0.871, P=0.046)$. 
Table 4: The correlation between PRF and BMI

\begin{tabular}{|c|c|c|c|c|}
\hline \multirow{2}{*}{ PRF } & \multicolumn{2}{|c|}{ BMI $\left(\mathrm{kg} / \mathrm{m}^{2}\right)$} & \multirow{2}{*}{$\chi^{2}$} & \multirow{2}{*}{$P$-value } \\
\hline & low group $(<23.0)$ & High group $(\geqq 23.0)$ & & \\
\hline Yes & 2 & 6 & 4.035 & $0.045^{*}$ \\
\hline No & 32 & 19 & & \\
\hline
\end{tabular}

${ }^{*} P<0.05$.

Table 5: Clinical monitoring parameters stratified by BMI

\begin{tabular}{|c|c|c|c|c|}
\hline \multirow{2}{*}{ Monitoring parameters } & \multicolumn{2}{|c|}{ BMI $\left(\mathrm{kg} / \mathrm{m}^{2}\right)$} & \multirow{2}{*}{$\chi^{2}$} & \multirow{2}{*}{$P$-value } \\
\hline & low group $(<23.0)$ & High group $(\geqq 23.0)$ & & \\
\hline Operation time (min) & & & 1.647 & 0.199 \\
\hline$<128$ & 22 & 12 & & \\
\hline$\geqq 128$ & 12 & 13 & & \\
\hline Drainage days & & & 0.152 & 0.697 \\
\hline$\geqq 4$ & 26 & 18 & & \\
\hline$>4$ & 8 & 7 & & \\
\hline Drainage volume (ml) & & & 0.136 & 0.712 \\
\hline$<557$ & 22 & 15 & & \\
\hline$\geqq 557$ & 12 & 10 & & \\
\hline Postoperative hospital time (days) & & & 7.896 & $0.005^{*}$ \\
\hline$<14$ & 30 & 14 & & \\
\hline$\geqq 14$ & 4 & 11 & & \\
\hline
\end{tabular}

${ }^{*} P<0.05$.

Besides serving for lipid storage, adipose tissue is now recognized as an important endocrine organ [32, 33], secreting hormones such as adiponectin, leptin, interleukin (IL)-6, tumor necrosis factor $\alpha$, IL-1 $\beta$, and estrogen, most of which are linked to tumor proliferation, angiogenesis, invasion and metastasis [6-8]. Recent research suggests that DNA methylation changes as BMI increases [34].

There are several limitations in the present study. First, the data was retrospectively collected in a single center, and the sample size was limited. Given that, more samples and further investigation are necessary to expand on these findings in the future. Secondly, the BMI standard that is specific for Asian populations was adopted in this research, which has a lower threshold for overweight and obesity compared to the WHO classification $[1,35]$. It remains unclear whether this biased the results, since theoretically, the higher the BMI, the more severe the dysfunction and chronic inflammation induced by adipose tissue. Finally, although BMI is considered a measure of adiposity, not all overweight or obese people demonstrate impairment, and some individuals with normal weight are impaired [36]. Therefore, further biomarkers are needed in addition to clinical measures.

\section{MATERIALS AND METHODS}

\section{Ethics}

The Ethics Committee of First Affiliated Hospital of China Medical University approved this retrospective study. The research was performed in accordance with the guidelines of the Ethics Committee, and conformed with the Declaration of Helsinki.

\section{Patients}

We conducted a retrospective analysis of the clinical data of $59 \mathrm{MG}$ patients, who had undergone transsternal thymectomy at our institute from June 2011 to May 2016. Patients who had received video-assisted thoracoscopic surgery were excluded from this study, to prevent bias with regard to inflammatory response, hospital stay, and surgery-related complications [37].

BMI was defined as the patient's weight divided by height squared $\left(\mathrm{kg} / \mathrm{m}^{2}\right)$. According to the standard criteria for Asian-Pacific populations, normal, overweight, and obese was defined as BMI $<23.0,23.0-24.9$, and 
$\geq 25.0 \mathrm{~kg} / \mathrm{m}^{2}$, respectively [38, 39]. Accordingly, the study population was stratified as either low or high BMI $(<23.0$ or $\geq 23.0 \mathrm{~kg} / \mathrm{m}^{2}$ ).

MG was diagnosed based on clinical manifestations, edrophonium test, electromyography, and serum autoantibody test [40]. Histological classification was in accordance with the revised World Health Organization (WHO), and clinical staging was based on the Masaoka system $[10,41]$.

\section{Statistical analysis}

All statistical data was analyzed using SPSS (Chicago, IL, USA) software, version 17.0. Categorical variables were assessed using Pearson's chi-squared $\left(\chi^{2}\right)$ test, Fisher's exact test, and analysis of variance (ANOVA). A ROC curve analysis was utilized to identify the optimal cutoff value of BMI for predicting PRF. A logistic regression model was applied to characterize associations between clinical parameters and major adverse complications. Statistical significance was established at $P<0.05$.

\section{CONCLUSIONS}

In conclusion, this study showed that a BMI in the overweight or obese range is positively associated with longer postoperative hospitalization and major adverse postoperative complications, especially PRF. The data supports that being overweight or obese is a risk factor for postoperative adverse situations in MG patients. Hence, appropriate care must be taken when transsternal thymectomy is necessary.

\section{Authors' contributions}

Xu-dong Liu designed the study, and drafted the manuscript. Ming-rui Shao and Lei Sun collected the data. Xin-shan Jia analyzed the data. Lin Zhang revised the manuscript. Wen-ya Li designed and supervised the study, and edited the manuscript. All the authors have read and approved the final manuscript.

\section{ACKNOWLEDGMENTS AND FUNDING}

This study was supported by National Natural Science Foundation of China (grant no. 81370100), Medical Education Research Project (grant no. 2016BJJ042), Natural Science Foundation of Liaoning Province (grant no. 2015020561) and the Fund for Scientific Research of The First Hospital of China Medical University (grant no. fsfh1514).

\section{CONFLICTS OF INTEREST}

There are no conflicts of interest.

\section{REFERENCES}

1. Lauby-Secretan B, Scoccianti C, Loomis D, Grosse Y, Bianchini F, Straif K. Body Fatness and Cancer-Viewpoint of the IARC Working Group. N Engl J Med. 2016; 375:794-798.

2. Wang YC, McPherson K, Marsh T, Gortmaker SL, Brown M. Health and economic burden of the projected obesity trends in the USA and the UK. Lancet. 2011; 378:815-825.

3. Hossain P, Kawar B, El Nahas M. Obesity and diabetes in the developing world - a growing challenge. N Engl J Med. 2007; 356:213-215.

4. Flegal KM, Carroll MD, Kit BK, Ogden CL. Prevalence of obesity and trends in the distribution of body mass index among US adults, 1999-2010. JAMA. 2012; 307:491-497.

5. Ng M, Fleming T, Robinson M, Thomson B, Graetz N, Margono C, Mullany EC, Biryukov S, Abbafati C, Abera SF, Abraham JP, Abu-Rmeileh NM, Achoki T, et al. Global, regional, and national prevalence of overweight and obesity in children and adults during 1980-2013: a systematic analysis for the Global Burden of Disease Study 2013. Lancet. 2014; 384:766-781.

6. Divella R, De Luca R, Abbate I, Naglieri E, Daniele A. Obesity and cancer: the role of adipose tissue and adipo-cytokinesinduced chronic inflammation. J Cancer. 2016; 7:2346-2359.

7. Iyengar NM, Hudis CA, Dannenberg AJ. Obesity and cancer: local and systemic mechanisms. Annu Rev Med. 2015; 66:297-309.

8. Deng T, Lyon CJ, Bergin S, Caligiuri MA, Hsueh WA. Obesity, Inflammation, and Cancer. Annu Rev Pathol. 2016; 11:421-449.

9. Spillane J, Higham E, Kullmann DM. Myasthenia gravis. BMJ. 2012; 345:e8497.

10. Li W, Miao Z, Liu X, Zhang Q, Sun L, Li P, Liu W, Zhang L. Thymic carcinoma patients with myasthenia gravis exhibit better prognoses. Int J Clin Oncol. 2016; 21:75-80.

11. Meriggioli MN, Sanders DB. Autoimmune myasthenia gravis: emerging clinical and biological heterogeneity. Lancet Neurol. 2009; 8:475-490.

12. Carr AS, Cardwell CR, McCarron PO, McConville J. A systematic review of population based epidemiological studies in Myasthenia Gravis. BMC Neurol. 2010; 10:46.

13. Wolfe GI, Kaminski HJ, Aban IB, Minisman G, Kuo HC, Marx A, Strobel P, Mazia C, Oger J, Cea JG, Heckmann JM, Evoli A, Nix W, et al. Randomized Trial of Thymectomy in Myasthenia Gravis. N Engl J Med. 2016; 375:511-522.

14. Gilhus NE. Myasthenia Gravis. N Engl J Med. 2016; 375:2570-2581.

15. Liu Z, Feng H, Yeung SC, Zheng Z, Liu W, Ma J, Zhong FT, Luo H, Cheng C. Extended transsternal thymectomy for the treatment of ocular myasthenia gravis. Ann Thorac Surg. 2011; 92:1993-1999.

16. Bamgbade OA, Rutter TW, Nafiu OO, Dorje P. Postoperative complications in obese and nonobese patients. World J Surg. 2007; 31:556-560; discussion 561. 
17. Montane B, Toosi K, Velez-Cubian FO, Echavarria MF, Thau MR, Patel RA, Rodriguez K, Moodie CC, Garrett JR, Fontaine JP, Toloza EM. Effect of Obesity on Perioperative Outcomes After Robotic-Assisted Pulmonary Lobectomy. Surg Innov. 2017; 24:122-132.

18. Sergesketter A, Elsamadicy AA, Gottfried ON. Impact of Obesity on Complications and 30-Day Readmission Rates After Cranial Surgery: A Single Institutional Study of 224 Consecutive Craniotomy/Craniectomy Procedures. World Neurosurg. 2017.

19. Thomas CE, Mayer SA, Gungor Y, Swarup R, Webster EA, Chang I, Brannagan TH, Fink ME, Rowland LP. Myasthenic crisis: clinical features, mortality, complications, and risk factors for prolonged intubation. Neurology. 1997; 48:1253-1260.

20. Kalita J, Kohat AK, Misra UK. Predictors of outcome of myasthenic crisis. Neurol Sci. 2014; 35:1109-1114.

21. Ando T, Omasa M, Kondo T, Yamada T, Sato M, Menju T, Aoyama A, Sato T, Chen F, Sonobe M, Date H. Predictive factors of myasthenic crisis after extended thymectomy for patients with myasthenia gravis. Eur J Cardiothorac Surg. 2015; 48:705-709; discussion 709.

22. Gronseth GS, Barohn RJ. Practice parameter: thymectomy for autoimmune myasthenia gravis (an evidence-based review): report of the Quality Standards Subcommittee of the American Academy of Neurology. Neurology. 2000; 55:7-15.

23. Kas J, Kiss D, Simon V, Svastics E, Major L, Szobor A. Decade-long experience with surgical therapy of myasthenia gravis: early complications of 324 transsternal thymectomies. Ann Thorac Surg. 2001; 72:1691-1697.

24. Trayhurn P. Hypoxia and adipocyte physiology: implications for adipose tissue dysfunction in obesity. Annu Rev Nutr. 2014; 34:207-236.

25. Ye J, Gao Z, Yin J, He Q. Hypoxia is a potential risk factor for chronic inflammation and adiponectin reduction in adipose tissue of ob/ob and dietary obese mice. Am J Physiol Endocrinol Metab. 2007; 293:E1118-1128.

26. Thorn CE, Knight B, Pastel E, McCulloch LJ, Patel B, Shore AC, Kos K. Adipose tissue is influenced by hypoxia of obstructive sleep apnea syndrome independent of obesity. Diabetes Metab. 2017.

27. Protani M, Coory M, Martin JH. Effect of obesity on survival of women with breast cancer: systematic review and metaanalysis. Breast Cancer Res Treat. 2010; 123:627-635.

28. Karagozian R, Derdak Z, Baffy G. Obesity-associated mechanisms of hepatocarcinogenesis. Metabolism. 2014; 63:607-617.
29. Michelotti GA, Machado MV, Diehl AM. NAFLD, NASH and liver cancer. Nat Rev Gastroenterol Hepatol. 2013; 10:656-665.

30. Khandekar MJ, Cohen P, Spiegelman BM. Molecular mechanisms of cancer development in obesity. Nat Rev Cancer. 2011; 11:886-895.

31. Cantarutti A, Bonn SE, Adami HO, Gronberg H, Bellocco R, Balter K. Body mass index and mortality in men with prostate cancer. Prostate. 2015; 75:1129-1136.

32. Villarroya F, Cereijo R, Villarroya J, Giralt M. Brown adipose tissue as a secretory organ. Nat Rev Endocrinol. 2017; 13:26-35.

33. Kershaw EE, Flier JS. Adipose tissue as an endocrine organ. J Clin Endocrinol Metab. 2004; 89:2548-2556.

34. Wahl S, Drong A, Lehne B, Loh M, Scott WR, Kunze S, Tsai PC, Ried JS, Zhang W, Yang Y, Tan S, Fiorito G, Franke L, et al. Epigenome-wide association study of body mass index, and the adverse outcomes of adiposity. Nature. 2017; 541:81-86.

35. Campbell PT, Newton CC, Freedman ND, Koshiol J, Alavanja MC, Beane Freeman LE, Buring JE, Chan AT, Chong DQ, Datta M, Gaudet MM, Gaziano JM, Giovannucci EL, et al. Body Mass Index, Waist Circumference, Diabetes, and Risk of Liver Cancer for U.S. Adults. Cancer Res. 2016; 76:6076-6083.

36. Rosen ED, Spiegelman BM. What we talk about when we talk about fat. Cell. 2014; 156:20-44.

37. Raza A, Woo E. Video-assisted thoracoscopic surgery versus sternotomy in thymectomy for thymoma and myasthenia gravis. Ann Cardiothorac Surg. 2016; 5:33-37.

38. WHO Expert Consultation. Appropriate body-mass index for Asian populations and its implications for policy and intervention strategies. Lancet. 2004; 363:157-163.

39. Kroenke CH, Caan BJ, Prado C. The Optimal Body Mass Index Range for Patients With Colorectal Cancer-Reply. JAMA Oncol. 2016.

40. Berrih-Aknin S, Frenkian-Cuvelier M, Eymard B. Diagnostic and clinical classification of autoimmune myasthenia gravis. J Autoimmun. 2014; 48-49:143-148.

41. Koga K, Matsuno Y, Noguchi M, Mukai K, Asamura H, Goya T, Shimosato Y. A review of 79 thymomas: modification of staging system and reappraisal of conventional division into invasive and non-invasive thymoma. Pathol Int. 1994; 44:359-367. 